\title{
Student Design of a Sustainable Microgrid for Rural Kenya
}

\section{Prof. Henry Louie, Seattle University}

Dr. Henry Louie received the B.S.E.E. degree from Kettering University, the M.S. degree from the University of Illinois at Urbana-Champaign and the PhD degree in Electrical Engineering from the University of Washington in 2008. He is currently an Associate Professor in the Department of Electrical and Computer Engineering at Seattle University. Dr. Louie is a founding member and current Secretary of the IEEE Power \& Energy Society (PES) Working Group on Sustainable Energy Solutions for Developing Communities. He was the technical program co-chair of the 2012 IEEE Global Humanitarian Technology Conference. Since 2011, he has been the IEEE PES Vice President of Membership \& Image. He is a Distinguished Lecturer of the IEEE on the topics of energy poverty and remote community microgrids.

\section{Mr. Steve Szablya, Seattle University}

Steve Szablya received a B.S. in Electrical Engineering from Washington State University in 1983 and an MBA degree from Washington State University in 1985 and is a licensed Professional Engineer in the state of Washington. He is an adjunct professor at Seattle University for the Electrical and Computer Engineering department advising senior design projects, including humanitarian projects for which he co-authored several papers with Dr. Henry Louie. He has installed several off grid systems in Africa and is member of the IEEE Community Solutions Initiative, finding appropriate energy solutions for impoverished communities off the power grid.

\section{Dr. Agnieszka Miguel, Seattle University}

Agnieszka Miguel joined the Department of Electrical and Computer Engineering at Seattle University in the Fall of 2004. Dr. Miguel received her Ph.D. in Electrical Engineering in 2001 from the University of Washington, and MSEE and BSEE from Florida Atlantic University in 1996 and 1994. Dr. Miguels research interests involve image processing, pattern recognition, machine learning, wavelets, and image and video compression. She is passionate about active learning and strategies to improve electrical and computer engineering education, as well as increasing the number of women in engineering. She is a PI on an NSF S-STEM ECE Scholars grant, which provides scholarships and academic support to financially needy and academically strong transfer students. Dr. Miguels teaching interests include MATLAB, circuits, linear systems, signal processing, digital image processing, and data compression. Dr. Miguel is a member of the IEEE, ASEE, SWE, and Tau Beta Pi. She has held several officer positions within the American Society for Engineering Education (Campus Representative, 2012-2013 ECE Division Chair, and 2013-2015 Chair Elect of the ASEE PNW Section). 


\section{A Sustainable Student Design of an Energy Kiosk for Rural Kenya}

\section{Introduction}

A lack of regular access to electricity is a persistent and stifling challenge for nearly 1.2 billion people, approximately half of whom live in Sub-Saharan Africa ${ }^{1}$. To eliminate this form of energy poverty requires a substantial mobilization of capital $-\$ 300$ billion by some estimatesand a workforce of engineers that are trained and prepared to design and implement technological solutions in the context of Less Economically Developed Countries (LEDCs) ${ }^{2}$.

Electrification approaches can be broadly partitioned into two categories: grid-connected and off-grid. In the former, the centralized national grid is expanded or otherwise enhanced to serve additional people. It is estimated that grid-connected electricity service will be viable for an additional 470 million people ${ }^{2}$. However, 70 percent of rural residents—generally those living more than $20 \mathrm{~km}$ from the existing grid-will likely not have a connection to the centralized grid in the foreseeable future ${ }^{2}$. Rather, they will be served by off-grid solutions, which generally include mini/micro grids, energy kiosks (community charging stations), solar home systems, solar lanterns or some combination thereof ${ }^{2}$.

This paper describes a senior undergraduate electrical engineering capstone project at Seattle University in which the students gained first-hand experience designing and implementing an off-grid solution in an LEDC. In particular, four students designed and assisted in the installation of a $4.8 \mathrm{~kW}$ hybrid wind and solar energy kiosk as part of a larger multidisciplinary team of about 20 volunteer practitioners. The energy kiosk provides electricity to 70 families in rural Muhuru Bay, Kenya. The project is the grand prize winner of the 2014 National Council of Examiners for Engineering and Surveying (NCEES) Award for Connecting Professional Practice and Education.

This paper provides an overview of the project and highlights the technical and non-technical constraints encountered. Because the project was not conceived as an experiment to assess student learning, this paper is focused on describing the student experiences and identifying opportunities for learning outside what is commonly encountered in senior capstone programs. Future work will be directed toward incorporating formative and summative assessment of student learning on similar projects.

The remainder of this paper is arranged as follows. Section 2 describes the senior design program and project team. The project genesis and community need are described in Section 3. Section 4 provides an overview of energy kiosks in general. The design approach, considerations and constraints are described in Section 5. Special challenges faced by the students are described in Section 6. A summary of student learning is provided in Section 7. Conclusions and future work are provided in Section 8.

\section{Project Team}


The students were engaged in the project as part of the Senior Design program at Seattle University. The Senior Design program is taken by all senior engineering students and spans three sequential academic quarters from September to June. Most projects are identified and sponsored by companies near the university. Students are assigned to specific projects based upon their interests and abilities, and the needs of particular projects. A faculty advisor and a liaison engineer from the sponsoring company or organization provide guidance to the students as needed.

The Muhuru Bay Energy Kiosk project was unique in several ways. Rather than being sponsored by a company, the majority of the project was funded by an external grant from the foundation of a large international electrical equipment manufacturing company. The grant was awarded to Seattle University with the expectation that a multidisciplinary team of volunteer practitionersengineers, programmers, social scientists, tradespeople - collaborate on the project. The volunteer team, which consisted of about 20 people in addition to the students, worked in subteams, each addressing different aspects of the project. For example, there were teams charged with developing the business plan for the kiosk, training the kiosk staff, public relations, among others. The students would work in close coordination with these other teams. The students attended bi-weekly "all hands" meetings, where they would regularly report on their progress. This is in addition to the in-class presentations associated with the Senior Design course.

The students were charged with the technical design and specifications of the energy kiosk. Many factors would influence the design, including: best practices of energy development work in LEDCs; international and local electrical codes; component availability; and non-technical constraints and considerations. The scope of the project and the composition of the project team provided an enriching learning environment for the students.

\section{Project Genesis and Community Need}

Muhuru Bay, Kenya is a fishing village located on the shores of Lake Victoria, close to the Tanzanian border. Although a few small shops in the business district of Muhuru Bay are connected to the national grid, the vast majority of households are not. Most people rely on small single-wick kerosene lamps (see Figure 1) and flashlights or candles for lighting. Kerosene lamps are hazardous, noxious, expensive and produce low-quality light of generally less than 20 lumens, which is inadequate for studying or reading ${ }^{3}$. Approximately 4000 people live in the greater Muhuru Bay area, most of them surviving on a few dollars per day.

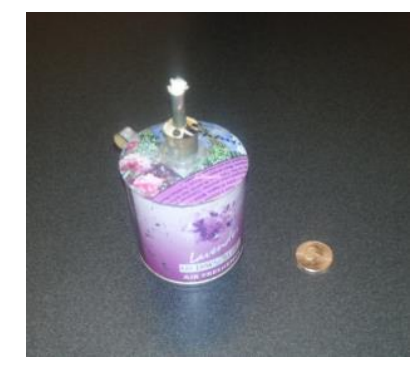

Figure 1. A typical kerosene lamp, fabricated from a used aerosol canister. A quarter is shown for size comparison. 
Five kilometers from the business district, beyond the reach of the grid, there is a private primary school named Kristy's Cape Academy. One of project team leaders has known the headmaster of the school for several years. The school serves approximately 300 students, many of whom were orphaned by HIV/AIDs. The school is underfunded and the lack of electricity in the classrooms and nearby homes was preventing students from studying in the evening. The idea of providing electricity service while supporting the school was born form early conversations with the community.

\section{Energy Kiosk Concept}

Developing off-grid solutions to electricity service provision is a challenging endeavor. Several possible models exist, such as microgrids, solar home systems, solar lanterns and energy kiosks ${ }^{4}$. Each has their advantages and disadvantages. Based upon initial impressions of the Muhuru Bay community, the project team felt that an energy kiosk was the most appropriate solution. Energy kiosks have received a lot of attention, with various groups experimenting with variations on the model, some more successfully than others ${ }^{5}$. The team used its own experience in energy development projects, as well as the knowledge base of the other practitioners from the IEEE Smart Village community to guide the project ${ }^{6}$.

An energy kiosk can be conceptualized as a retail outlet for electricity. Customers bring portable electronic devices or batteries that need to be recharged to the kiosk. Electronic devices, particularly mobile phones, have proliferated in the most remote areas, even those without electricity service. At the kiosk, customers pay a fee for their batteries to be charged and retrieve them later. A typical fee to recharge a mobile phone battery is about $\$ 0.25$. In some cases, the energy kiosk offers dedicated portable battery kits (PBKs) that can be rented by a customer for a monthly fee. The fee covers any recharging that may be done during the month. The monthly fee is usually set to be near what a family would normally spend on kerosene and candles, often $\$ 10$ to $\$ 13$ per month. Other payment models also exist ${ }^{5}$. Energy kiosks may sell other goods and services, such as cold soda and mobile phone talk time credit. Energy kiosks can be gridconnected, but many are not. Those that are not grid connected often rely on solar photovoltaic (PV) power.

The project team's initial high-level conception of the project was for there to be a hybrid windand solar-powered energy kiosk that would offer PBKs for rental as well as provide electricity to the headmaster's house and school. The headmaster's house is located across a small dirt road from the school. The energy kiosk would operate administratively under the school as a social enterprise where profits from its operation, after accounting for salaries, maintenance and depreciation, would support the school.

\section{Design Approach}

At the start of the academic year, the student team was provided with a scope of work. Their work included determining the capacities of the solar panels, wind turbines and station batteries; developing component specifications for controllers and converters; designing the complete wiring diagram for the power source, controls, and power transmission to the kiosk; and determining the physical placement of the wind turbines. The students' design accounted for all of the technical issues to provide a safe utility-grade installation using international and local electrical codes. 
Several key inputs that would influence the final design were not known when the students began working on the project in September. They would be determined based on the findings of an assessment trip in December, and the inputs and constraints from the other teams. However, a preliminary design was made by the students based on known constraints, assumptions and input from the larger team's past experiences with energy kiosks.

One important constraint imposed by the primary funder of the project is that both wind turbines and PV panels be used to power the kiosk. Furthermore, the rated capacities of each were to be similar, but not necessarily the same. The specific characteristics of the turbines and PV panels were left for the students to determine.

\section{Preliminary Design}

The students used HOMER, a renewable energy modeling software program, to perform the preliminary design ${ }^{7}$. HOMER allowed the students to simulate the system and choose the most costeffective combination of station batteries, PV panels, converters, and wind turbines. Students designing a similar system in, for example, the U.S. would likely be able to find reliable solar and wind resource data from a nearby weather station to input into the simulation. Measured meteorological data from rural Kenya is scarce. The students performed several sensitivity studies to arrive at a conservative design that should be suitable even with large variations in wind speed and irradiance from the estimated values.

The preliminary design suggested approximately $7012 \mathrm{Ah}, 12$ VDC PBKs and a continuous $100 \mathrm{~W}$, 240 VAC $50 \mathrm{~Hz}$ load for the headmaster's house and school could be served by a $3.88 \mathrm{~kW}$ system while remaining within the project budget. The system would use two $1 \mathrm{~kW}$ wind turbines and 1.88 $\mathrm{kW}$ of PV panels. Creating a preliminary design also allowed the system topology to come into focus. A schematic is shown in Figure 2. The PV panels are connected to a DC bus through a charge controller with maximum power point tracking (MPPT) functionality. The two wind turbines produced rectified DC and are connected to the same DC bus. A controller connects the DC bus to a diversion load in situations when the station batteries are fully charged yet there is power being produced from the wind turbine. A diversion load is important to include in the design because whereas PV panels may be open-circuited to prevent overcharging, wind turbines cannot, as they run the risk of over-speeding when open-circuited. The station batteries provide a buffer between the power generation and consumption. The system load is supplied through an AC inverter. 


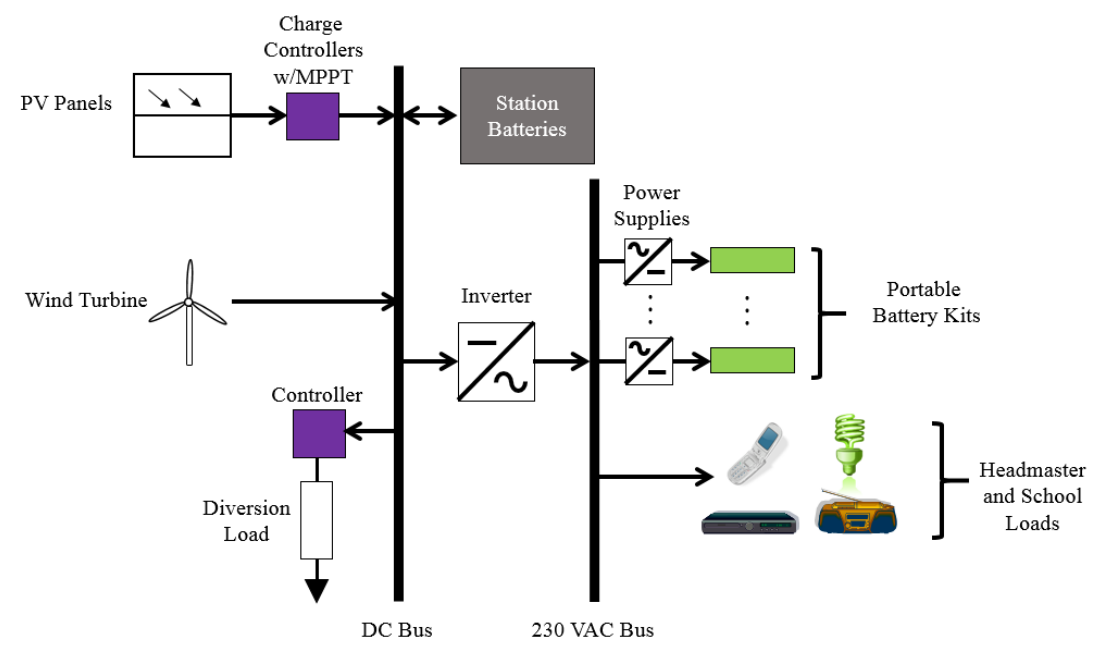

Figure 2. Preliminary design of the energy kiosk.

Although HOMER computed that a system with more PV panels and no wind turbines would be the most cost-effective design, the wind turbines needed to be included at the behest of the funder. This was an important learning experience for the students, as they saw how a non-technical constraint influenced the technical design of the system.

\section{Project Assessment Trip}

An assessment trip in December provided data and guidance to allow the students to refine the preliminary design. Although no student traveled to Muhuru Bay during the assessment trip due to travel restrictions in place at the time, the students learned the motivation behind and the importance of assessment trips: meet with community stakeholders; conduct community surveys; inspect the site location; meet with potential vendors of the PBKs and other system components; and identify any possible cultural or environmental challenges.

Of critical importance to projects that are designed to operate as self-sustaining businesses is the community market survey. This survey is used to assess community energy needs, and importantly, provide input data for determining the price points for the electricity services offered by the kiosk and the market potential for these services. A thorough description of the survey, the responses and how they were used to inform the business plan are provided in another article ${ }^{8}$.

\section{Final Design}

Findings from the assessment trip helped the students refine the design of the project. One important decision affecting the design was the selection of particular model and quantity of PBKs. This is important because recharging the PBKs would be the largest load on the system. Depending on the state of charge, most PBKs can consume between $10 \mathrm{~W}$ and $60 \mathrm{~W}$ when recharging, with charging efficiency of approximately 70 percent. A fully discharged PBK takes between seven and ten hours to recharge. 
Samples of various PBK models were taken to Muhuru Bay and feedback was gathered from focus groups. Based on this feedback and other technical and economic considerations, the BBOXX 12 was selected ${ }^{9}$. The BBOXX 12 is a $12 \mathrm{Ah}, 12 \mathrm{~V}$ PBK. It features a ruggedized case surrounding a sealed lead-acid battery. There are four ports for connecting efficient LED lights $(1.25 \mathrm{~W}, 100 \mathrm{Lm})$, two USB ports and adapters for mobile phone charging, and a low voltage disconnect to protect the battery. The PBK can be recharged using AC.

There was an important learning opportunity for the students in selecting the PBK. Although there are many manufacturers of PBKs that satisfy the technical requirements of the project, not all had an in-country presence in Kenya. Managing the process, cost and uncertainty of importing goods into many sub-Saharan African countries including Kenya is not trivial. Delays of weeks or months are common, even for those familiar with the process. Additionally, an incountry supplier makes repair, replacement, support and warranty work easier and more economically feasible. There is also the opportunity for environmentally safe disposal of the batteries through the vendor. Suppliers with an in-country preference were given preference in PBK selection. These are practical supply chain and life cycle considerations that many student design projects do not encompass.

The recharging of the PBKs would be the most significant load on the system. It would drive the final sizing of the PV panels, wind turbines, station batteries and the inverter. However, the load profile of the PBKs depends on how often and what time each PBK is returned. This is difficult to estimate for a community that has never had access to electricity. A conservative estimate informed by data collected from the assessment trip is that the PBKs would be recharged no more frequently than every other day. Data from the assessment trip suggested that the demand for the PBK rental service would exceed what could be supplied by the initial capital budget, which could purchase at most 70 PBKs. In anticipation of future expansion, the conductor sizing and other apparatus should be able to accommodate 100 PBKs. The final design of the energy kiosk is shown in Figure 3. 


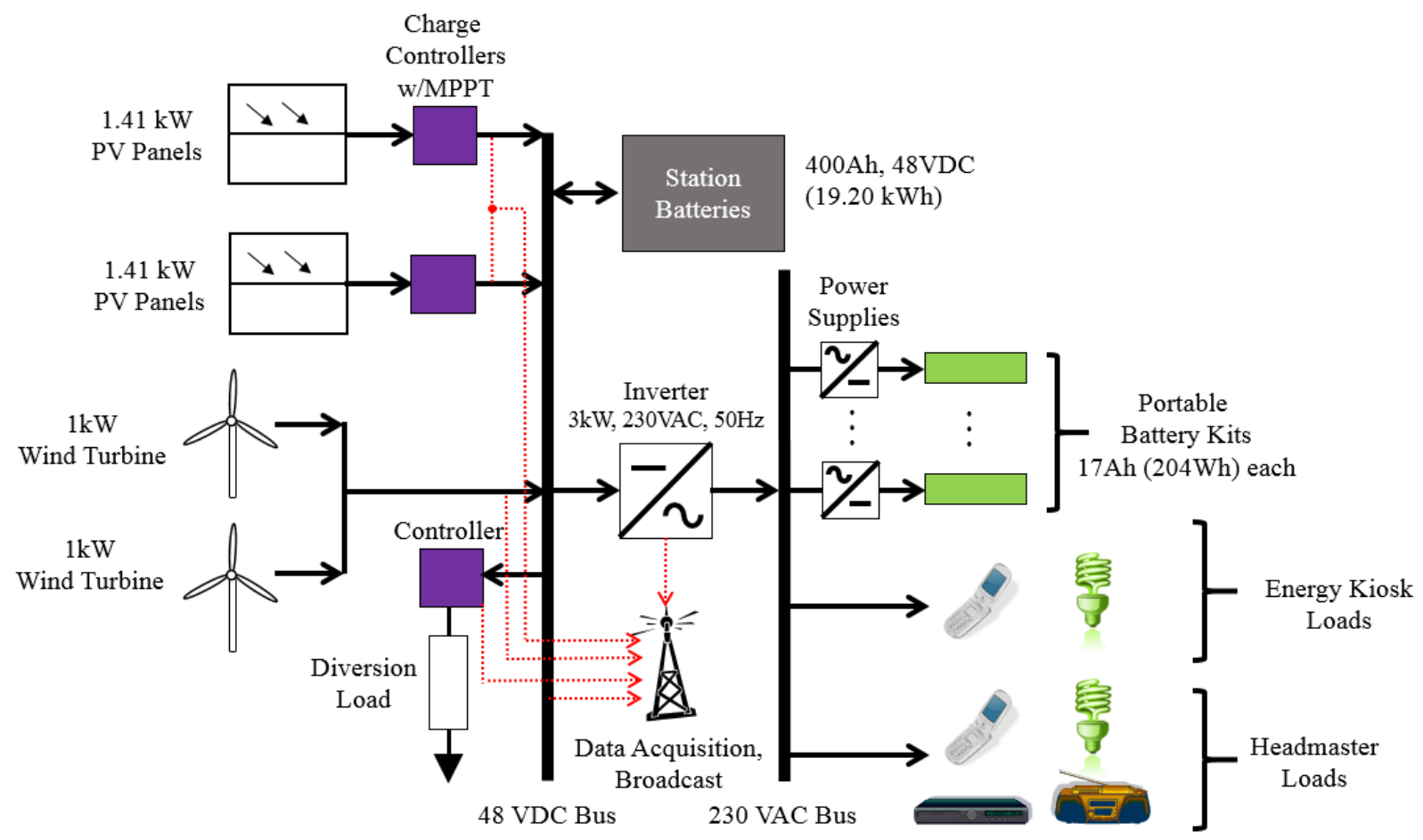

Figure 3. Final design of the energy kiosk.

The refined design was used to write a Request for Proposal (RFP) from three Kenyan vendors to supply equipment (other than the PBKs) and install the system. A core element in many development projects that are associated with a university is that the team of student volunteers do most of the installation. Hiring a contractor to do this work is anathema to this mode of operation. However, the students learned the important concept of "reverse out-sourcing" that suggests that when possible, using an indigenous company and workers to do the installation is more beneficial for capacity-building than using free volunteer labor from abroad. Additionally, in-country contractors are able to service the equipment, something many students are unable to do following graduation.

The site plan in Figure 4 shows the property and where the equipment is located. The PV panels are located on the roof of the headmaster's house. A control room inside the house contains the station batteries and other equipment. The wind turbines will be located approximately $30 \mathrm{~m}$ northeast of the house and the energy kiosk will be located another $30 \mathrm{~m}$ east of the wind turbines near the road. The energy kiosk is served by a 240 VAC supply line. 


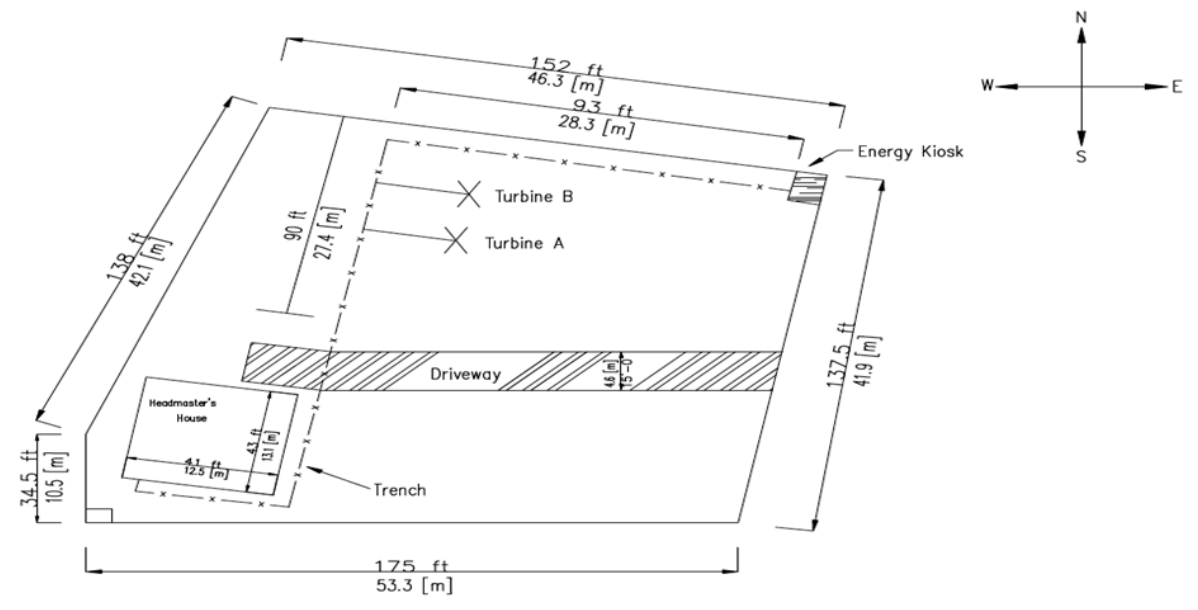

Figure 4: The compound of the headmaster's house, showing location of the wind turbines and energy kiosk.

\section{Economic Considerations}

The students worked with volunteer engineers in writing the RFP and reviewing the proposals received - an experience most undergraduate students do not receive. The final capital equipment totaled approximately $\$ 37,000$. The cost breakdown is shown in Figure 5 .

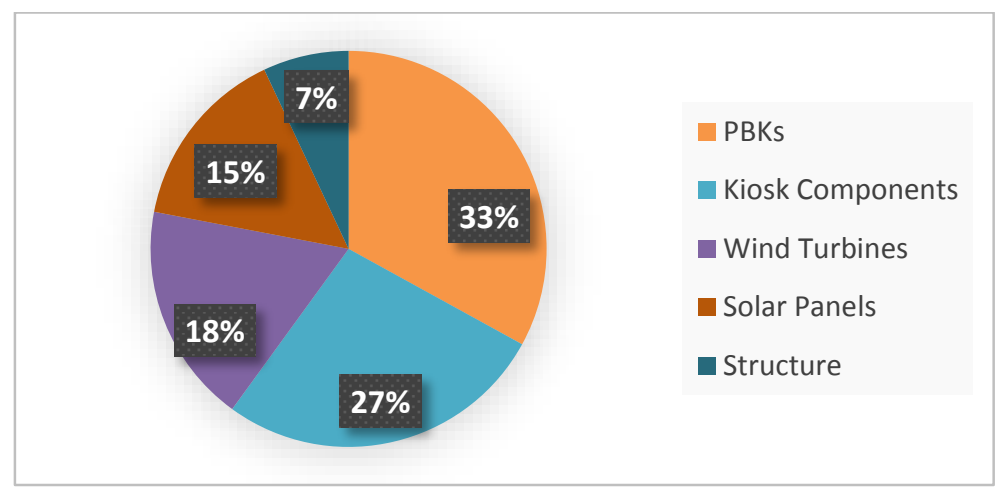

Figure 5. Breakdown of capital costs for the energy kiosk.

The large expense of PBKs and their relatively short lifespan - approximately two yearsrequires financial discipline coupled with a sound business plan. Money must be set aside each month to pay for the eventual replacement of the PBKs when they inevitably fail. Although developing the business plan was not part of the students' scope of work, they nonetheless were exposed to the critical role that it plays in maintaining the sustainability of a project.

\section{Socio-cultural Considerations}

Most development projects have a socio-cultural impact on the community, and the Muhuru Bay energy kiosk is no different. These aspects must be identified and planned for, otherwise the long-term sustainability of the project will be jeopardized ${ }^{10}$. One important aspect to be 
considered is the inequality of PBK distribution. Because at most 70 families would be initially able to rent PBKs, determining who these families are in a transparent, equitable way is important. After consulting with the headmaster, one condition of participating in the program was that at least one child in the family had to attend the school. This reinforces the social aim of the project that students should benefit from it. A lottery system was used to select amongst the group of eligible families. During implementation, the community seemed to agree that this was a just way of determining eligibility.

Another consideration is the relatively sudden influx of capital bestowed upon Kristy's Cape Academy and its headmaster. The community perception is that the headmaster himself is the beneficiary of a substantial donation. Furthermore, the prominence of the wind turbines sitting atop $13 \mathrm{~m}$ towers may attract unwanted attention as an indicator of wealth or hostility. As a result there are security and safety concerns. To mitigate against this, the kiosk and all components were sited to be within the headmasters secure compound and several external nighttime security lights are place around the perimeter.

\section{Other Challenges}

As with many real-world projects, the Muhuru Bay Energy Kiosk faced many challenges and changes that the students had to respond to. Among them was that in June, near the end of the academic year, the selected PBKs were discontinued by the supplier. The student team had to quickly re-run simulations and redo calculations to determine the impact of switching to another model, the BBOXX 17 (a 17 Ah version of the BBOXX 12). The design was changed to increase the capacity of the PV system from $1.8 \mathrm{~kW}$ to $2.8 \mathrm{~kW}$ to accommodate for a possible increase in energy consumption.

Another significant change was that the school was to be relocated to another parcel of land. The decision was made not to run the supply cable to the school until the school was relocated.

\section{Implementation}

After successfully completing the design, two students participated in the implementation trip to Kenya during the summer following their graduation. Several volunteer practitioners also participated in the trip. The Kenyan contractor performed the majority of the installation. The students and other project team members assisted in some installation tasks, verified the installation was done to specification, set up the data logging and broadcast system, and worked on the community awareness campaign. The implemented system is shown in Figure 6 and Figure 7. 


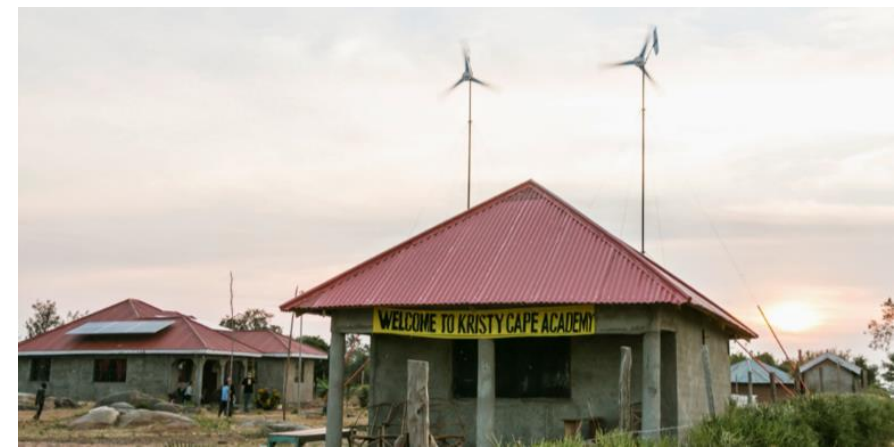

Figure 6: Energy kiosk (foreground) and headmaster's house (background). Source: Eli Patten

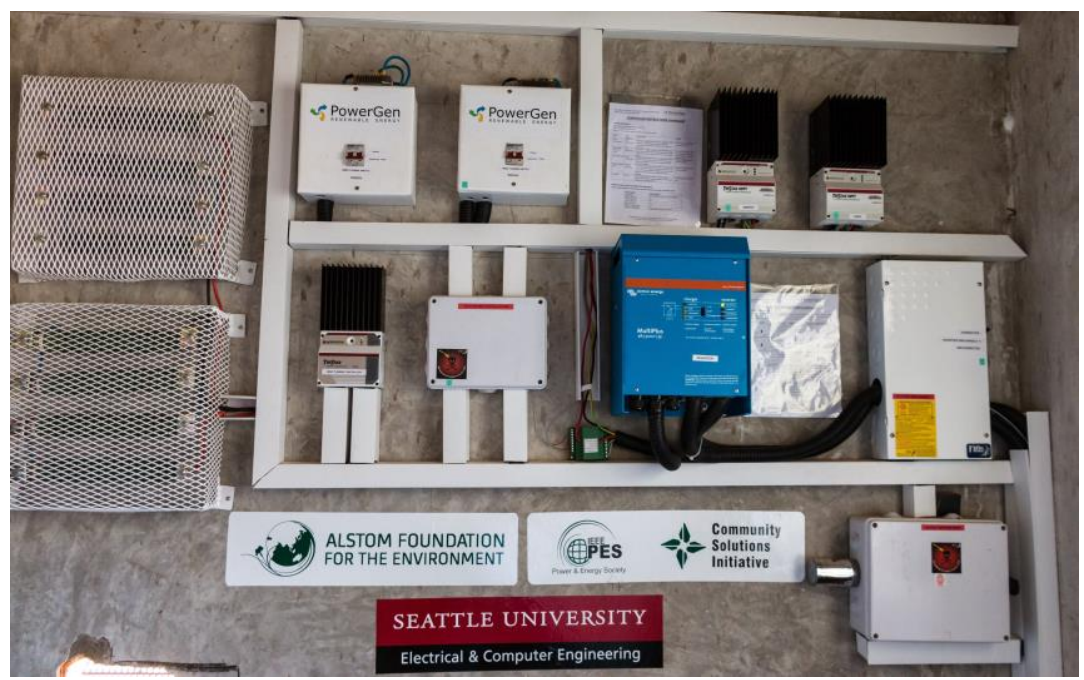

Figure 7: Control room of the energy kiosk showing inverter, PV and diversion load controllers, diversion loads and wind turbine cut-off switches. Source: Eli Patten

Perhaps too often, students and volunteers participate in development projects for the spectacle of traveling to an impoverished area and contributing to a project with little lasting value.

However, for some students this immersion is eye-opening and life changing. One of the two students that participated in the implementation trip continues to regularly meet with the other volunteers as the next project is planned. The other is in South America, looking for partners to begin an electricity service social enterprise.

\section{Summary of Student Learning}

The Senior Design program has a number of project-independent technical and non-technical course learning outcomes. Student learning is assessed throughout the year, primarily based on written reports, oral presentations, design reviews, peer-reviews and faculty observations. The Muhuru Bay project itself was not designed or intended to assess student learning of additional outcomes. However, because of the uniqueness of the project, it is expected that students were exposed to and learned additional concepts. 
A follow-up survey was sent to the four participating students approximately nine months after the academic year ended. The students were asked to reflect on their involvement in the project, and then rate how their participation affected their learning in six areas, as indicated in the following:

1. Ability to work as part of a large interdisciplinary team of technical and non-technical professionals.

2. Ability to write a real request for proposals and evaluate the responses.

3 Ability to consider life cycle issues when specifying components and identifying vendors.

4.Ability to appreciate the importance and usefulness of data gathering within the community.

5.Ability to appreciate importance of social, cultural and economic considerations and constraints and how they can influence technical design.

6. Ability to anticipate and overcome challenges in communication.

The students were instructed to assign a score between 1 and 5 (inclusive) for each of the questions, where a 1 indicated a perceived no improvement in the ability, and a 5 indicated a perceived great improvement in the ability. All four students responded to the survey. The numerical averages are provided in Table 1.

Table I. Survey Responses

\begin{tabular}{|l|c|}
\hline \multicolumn{1}{|c|}{ Question } & Average Response \\
\hline Q1 (work on interdisciplinary team) & 4.75 \\
\hline Q2 (write/evaluate proposals) & 4.50 \\
\hline Q3 (lifecycle issues) & 4.00 \\
\hline Q4 (importance of data-gathering) & 5.00 \\
\hline Q5 (appreciate social, cultural, economic constraints) & 4.75 \\
\hline Q6 (anticipate and overcome challenges in communication) & 4.75 \\
\hline
\end{tabular}

The students indicated that the project improved their learning in all areas, with averages ranging between 4.00 and 5.00. The lowest average score was for learning of lifecycle issues, whereas the highest was for learning of the importance of data gathering. In general, the topics receiving the highest average scores were related to the students learning the local context of the project.

The generalization of the survey results is cautioned, due to the small sample size and lack of a control group. However, the results do point to future areas of possible educational research.

\section{Conclusions}

This paper described a unique senior design experience in which four students worked within a larger project team to design and implement an energy kiosk in a less economically developed country.

At the time of this writing, the Muhuru Bay energy kiosk has been in operation for nine months. To date it has produced over $1 \mathrm{MWh}$ of energy. Seattle University is continuing to receive nearreal time data from the project, which are routinely monitored and even used in various class exercises. The use of Kenyan suppliers proved to be wise as there have been two device failures, 
which were promptly replaced under the terms of the warranty. A six-month follow-up trip showed the system to be behaving as designed.

Based upon the experience with this project, future projects will be designed to formally and rigorously capture and measure student learning outcomes, which were not included in this project.

\section{References}

1. Sustainable Energy for All, Global Tracking Framework, [Online]. Available: http://www.se4all.org/2013/10/29/se4all-global-tracking-framework/

2. International Energy Agency, Energy for all: Financing access for the poor, World Energy Outlook, Oct. 2011.

3. E. Mills, Technical and Economic Performance Analysis of Kerosene Lamps and Alternative Approaches to Illumination in Developing Countries, Jun. 2003.

4. H. Louie, E. O'Grady, S. Szablya, V. Van Acker, N. Kumar and R. Podmore, Rural Sub-Saharan Microgrids, IEEE Electrification Magazine, vol. 3, no. 1, pp. 7-15, DOI: 10.1109/MELE.2014.2380111, Mar. 2015.

5. Endeva, The Energy Kiosk Model: Current challenges and future strategies, Endeva Business Model Library, vol 1, Oct. 2014

6. R. S. Larsen, R. Podmore, M. Lacourciere, P. Ryan, D. G. Welbourn, and D. Wessner, The CSI story: IEEE PES Community Solutions Initiative, IEEE Global Humanitarian Technology Conference (GHTC), pp.129,134, 20-23

Oct. 2013

7. Homer Energy, [Online]. Available: http://homerenergy.com/

8. V. Van Acker, S. J. Szablya, H. Louie, J. McLean Sloughter, A. S. Pirbhai, Survey of energy use and costs in rural Kenya for community microgrid business model development, IEEE 2014 Global Humanitarian Technology Conference (GHTC), pp.166,173, 10-13 Oct. 2014

9. BBOXX, Solar Products, [Online]. Available: http://www.bboxx.co.uk/our-products/

10. H. Louie, P. Dauenhauer, M. Wilson, A. Zomers and J. Mutale, Eternal Light: Ingredients for Sustainable OffGrid Energy Development, IEEE Power \& Energy Magazine, vol. 12, no. 3, pp. 70-78, DOI:

10.1109/MPE.2014.2317093, Jul./Aug. 2014. 